\title{
Vaccination as a Preventive Tool of Infection for Patients With Autoimmune Inflammatory Rheumatic Diseases
}

\author{
Yoon-Kyoung Sung, M.D., Ph.D., MPH \\ Department of Rheumatology, Hanyang University Hospital for Rheumatic Diseases, Seoul, Korea
}

Patients with autoimmune inflammatory rheumatic diseases (AIIRD) are prone to infections because of the underlying autoimmune disease, comorbidities, as well as the use of immunosuppressive agents including glucocorticoid, disease and disease-modifying anti-rheumatic drugs. In particular, as targeted therapies such as biologic agents and small molecule inhibitors have been developed and widely used, the possibility of new opportunistic infections different from conventional immunosuppressants has increased $[1,2]$. The necessity of vaccination for patients with AIIRD is agreed, but the coverage of vaccination is still not high enough [3-5]. A recent study conducted in Canada reported that vaccination coverage against influenza was $48.5 \%$ of patients with rheumatoid arthritis (RA), $42.0 \%$ of patients with a systemic rheumatic diseases (SRD) and $31.9 \%$ of patients with ankylosing spondylitis (AS), lower than that of the general population $(58.5 \%)$; and that vaccination coverage against pneumococcal infection was $42.0 \%$ of patients with RA, $37.8 \%$ of patients with SRD and $29.7 \% \%$ of patients with AS, again lower than that of the general population $(53.2 \%)$. In the case of herpes zoster, the vaccination coverage of those with RA was merely $5.6 \%$ [5]. The data in South Korea will not be significantly different, though a systematic survey needs to be done. These low vaccination coverage rates can be attributed to two reasons. First, there is a concern that antigenic stimulation of vaccination might trigger a nonspecific immune response, potentially resulting in increased activity of rheumatic disease [6-8]. Second, the defective immune functions by immunosuppressive agents could decrease the efficiency or immunogenicity from vaccination [9-11]. Apart from these probable grounds, low vaccination coverage is a global phenomenon $[4,12-16]$, which can be attributed to the low level of pnysicians' interest in and request for vaccination $[17,18]$. Unlike these concerns, however, it has been reported that vaccination can reduce infection, boost immunity and resultantly decrease the number of hospitalization or visits to emergency rooms due to infection [11]. Lots of studies also reported that vaccination in a stable state helps prevent infectious diseases among patients with AIIRD.

Until now, several clinical practice guidelines have been developed around the world to promote the interest of physicians and patients and the lack of understanding of up-to-date knowledge, and continuous efforts have been made to induce changes in practice behaviors. To meet changes in practice environments and trends in the development of practice guidelines at home and abroad, the necessity of practice guidelines for vaccination of patients with AIIRD has also been continuously raised in South Korea, taking into account health care systems, practice behaviors and distinct environmental characteristics in Korea.

Seo et al. [19] published the guidelines for vaccination of Korean patients with AIIRD and the guideline was developed in collaboration with the Korean Society of Infectious Diseases (KSID) and the Korean College of Rheumatology (KCR) as the first AIIRD vaccination guideline developed in South Korea. A total of 2 years and 6 months from June, 2017 to December, 2019 were spent to develop the guideline. The guideline was intended for

Received : September 22, 2020, Accepted : September 23, 2020

Corresponding to : Yoon-Kyoung Sung (iD http://orcid.org/0000-0001-6691-8939

Department of Rheumatology, Hanyang University Hospital for Rheumatic Diseases, 222 Wangsimni-ro, Seongdong-gu, Seoul 04763, Korea. E-mail : sungyk@hanyang.ac.kr

Copyright (c) 2020 by The Korean College of Rheumatology.

This is an Open Access article, which permits unrestricted non-commerical use, distribution, and reproduction in any medium, provided the original work is properly cited. 
experts in rheumatology and infectious diseases, as well as for primary care providers who encounter patients with AIIRD with the aim of informing them of primary vaccines for the patients, methods to administer vaccines and considerations in the process [19]. This is significant in two ways. First, this guideline was developed by a group of experts in Korea where so far no practice guideline had been available in Korea, thus mainly relying on guidelines developed in other countries. Various guidelines are available and the content also varies depending on country and region. If the guideline adopted in Korea has to be replaced whenever there are any updates in each guideline, it will be difficult to set up a consistent framework for vaccination in Korea. It is also difficult for individual physicians to correctly identify whether each guideline developed in other countries is an evidencebased guideline. Against this backdrop, this guideline written in Korean and developed by experts in Korea is expected to significantly contribute to the standardization of vaccination methods for patients with AIIRD in Korea. Second, this guideline will provide an opportunity to raise the awareness of administering vaccines itself.

This guideline states in the general recommendations that patients with AIIRD need vaccination, and recommends establishing treatment strategies and surveying the vaccination history of patients with AIIRD prior to administering individual vaccines. It also mentions the timing of vaccination, the necessity of vaccination to prevent endemic diseases for patients with AIIRD who contemplate travel, and the risk of yellow fever vaccination. The necessity of vaccination for the family members of AIIRD patients and their care givers is also highlighted and every situation that doctors face in the process of diagnosing and treating patients with AIIRD is covered in the guideline. This demonstrates that rheumatologists who see and examine patients in person should lead the vaccination of patients with AIIRD under the healthcare system in Korea, which is different from Europe with different social situations. The roles of primary physicians and rheumatologists are separated in Europe, consequently resulting in some differences between this guideline and the one that was recently published by European League Against Rheumatism (EULAR) [20].

As the guideline for vaccination of AIIRD patients is the first one published in Korea, it is a time to show policy-level consideration for them. That is, the reason why vaccination is given to the elderly and children free of charge is that we are well aware that they are vulnerable to infection and that once they are infected, the morbidity and mortality is tremendous. What about patients with AIIRD? Especially those who are receiving immunosuppressive treatment or those of advanced years? In order to increase their vaccination rates for protection, firstly, it is necessary to ensure physicians correctly recognize the importance of vaccination in patients with AIIRD, and, secondly, policy-level consideration for them and strong recommendations may be required. In addition, experts need to make efforts to update the guideline based on science-based grounds and to promote the awareness of physicians and patients.

I wish recommendations on COVID-19 (Coronavirus disease 2019) vaccines can be provided in the next revision of the vaccination guideline for patients with AIIRD.

\section{CONFLICT OF INTEREST}

No potential conflict of interest relevant to this article was reported.

\section{REFERENCES}

1. Martin-Mola E, Balsa A. Infectious complications of biologic agents. Rheum Dis Clin North Am 2009;35:183-99.

2. Furst DE. The risk of infections with biologic therapies for rheumatoid arthritis. Semin Arthritis Rheum 2010;39: 327-46.

3. Glück T, Müller-Ladner U. Vaccination in patients with chronic rheumatic or autoimmune diseases. Clin Infect Dis 2008;46:1459-65.

4. Hmamouchi I, Winthrop K, Launay O, Dougados M. Low rate of influenza and pneumococcal vaccine coverage in rheumatoid arthritis: data from the international COMORA cohort. Vaccine 2015;33:1446-52.

5. Qendro T, de la Torre ML, Panopalis P, Hazel E, Ward BJ, Colmegna I, et al. Suboptimal immunization coverage among canadian rheumatology patients in routine clinical care. J Rheumatol 2020;47:770-8.

6. Ferreira I, Isenberg D. Vaccines and biologics. Ann Rheum Dis 2014;73:1446-54.

7. Westra J, Rondaan C, van Assen S, Bijl M. Vaccination of patients with autoimmune inflammatory rheumatic diseases. Nat Rev Rheumatol 2015;11:135-45.

8. Han SH. Vaccination for patients with rheumatic diseases in the era of biologics. J Rheum Dis 2018;25:100-7.

9. Fomin I, Caspi D, Levy V, Varsano N, Shalev Y, Paran D, et al. Vaccination against influenza in rheumatoid arthritis: the effect of disease modifying drugs, including TNF alpha blockers. Ann Rheum Dis 2006;65:191-4.

10. Elkayam O, Paran D, Caspi D, Litinsky I, Yaron M, Charboneau $\mathrm{D}$, et al. Immunogenicity and safety of pneumococcal vaccination in patients with rheumatoid arthritis or systemic lu- 
pus erythematosus. Clin Infect Dis 2002;34:147-53.

11. Elkayam O, Amir S, Mendelson E, Schwaber M, Grotto I, Wollman J, et al. Efficacy and safety of vaccination against pandemic 2009 influenza A (H1N1) virus among patients with rheumatic diseases. Arthritis Care Res (Hoboken) 2011;63:1062-7.

12. Fernandez-Martinez S, Cortes X, Borrás-Blasco J, Gracia-Pérez A, Casterá ME. Effectiveness of a systematic vaccination program in patients with autoimmune inflammatory disease treated with anti-TNF alpha drugs. Expert Opin Biol Ther 2016;16:1317-22.

13. Costello R, Winthrop KL, Pye SR, Brown B, Dixon WG. Influenza and pneumococcal vaccination uptake in patients with rheumatoid arthritis treated with immunosuppressive therapy in the UK: a retrospective cohort study using data from the clinical practice research datalink. PLoS One 2016;11:e0153848.

14. Sandler DS, Ruderman EM, Brown T, Lee JY, Mixon A, Liss DT, et al. Understanding vaccination rates and attitudes among patients with rheumatoid arthritis. Am J Manag Care 2016;22:161-7.

15. Nguyen M, Lindegaard H, Hendricks O, Friis-Møller N. Factors associated with influenza and pneumococcal vaccine uptake among rheumatoid arthritis patients in Denmark invited to participate in a pneumococcal vaccine trial (Immunovax_RA). Scand J Rheumatol 2017;46:446-53.

16. Brocq O, Acquacalda E, Berthier F, Albert C, Bolla G, Millasseau E, et al. Influenza and pneumococcal vaccine coverage in 584 patients taking biological therapy for chronic inflammatory joint: a retrospective study. Joint Bone Spine 2016;83:155-9.

17. Ng B, McBain L, Grainger R. Rheumatologists fail to advise people with RA to get immunised, which matters if you are under 65: an audit in a New Zealand rheumatology service. N Z Med J 2016;129:72-8.

18. Lawson EF, Trupin L, Yelin EH, Yazdany J. Reasons for failure to receive pneumococcal and influenza vaccinations among immunosuppressed patients with systemic lupus erythematosus. Semin Arthritis Rheum 2015;44:666-71.

19. Seo YB, Moon SJ, Jeon CH, Song JY, Sung YK, Jeong SJ, et al. The practice guideline for vaccinating Korean patients with autoimmune inflammatory rheumatic disease. J Rheum Dis 2020;27:182-202.

20. Furer V, Rondaan C, Heijstek MW, Agmon-Levin N, van Assen S, Bijl M, et al. 2019 update of EULAR recommendations for vaccination in adult patients with autoimmune inflammatory rheumatic diseases. Ann Rheum Dis 2020;79:39-52. 